\title{
ANALYSIS OF METHODS OF AIRWAY MANAGEMENT IN MAXILLOFACIAL SURGERIES IN A TERTIARY CARE CENTRE AT PUDUCHERRY
}

\author{
Joseph Raajesh I', Deepak Paulose T22, Devakumari $S^{3}$
}

${ }_{1}^{1}$ Professor, Department of Anaesthesiology, Indira Gandhi Medical College and Research Institute, Puducherry.

${ }^{2}$ Assistant Professor, Department of Anaesthesiology, Indira Gandhi Medical College and Research Institute, Puducherry.

${ }^{3}$ Associate Professor, Department of Dental Sciences, Indira Gandhi Medical College and Research Institute, Puducherry.

ABSTRACT
BACKGROUND
Anaesthetic management of patients with oromaxillofacial surgeries poses quite a few challenges to both anaesthesiologist and
operating surgeons. This is because the corrective procedure demands fixation of fractures, repair of soft tissue injuries and
maintaining occlusion all without compromising the cosmetic aspect. Though securing the airway takes the precedence, it is of
paramount importance that it should not interfere with the surgical techniques.

\section{METHODS}

Seventy one patients of maxillofacial injuries, operated over a period of five years between February 2011 and December 2015 in Indira Gandhi Medical College Hospital at Puducherry were reviewed. All patients were reviewed in relation to age, type of injury, etiology, bones involved and method of airway management.

\section{RESULTS}

The major etiology of injuries were road traffic accidents (79\%). Majority of patients were young in the age group of 21-40 years $(55 \%)$. Fracture mandible (46\%) was the most common injury. Airway secured by nasotracheal route with direct visualization of vocal cords was the most common (90\%), followed by submental route $(10 \%)$.

\section{CONCLUSION}

This analysis showed in maxillofacial procedures, trauma is the leading cause in this part of India also. Male preponderance, maximum injuries are seen in third and fourth decade of life and other findings that are correlating well with other studies. Nasotracheal intubation is the method of choice in securing the airway during the maxillofacial procedures. Submental intubation can be considered as a viable option when nasotracheal intubation is not possible due to the involvement of base of the skull or midfacial fractures.

\section{KEYWORDS}

Airway Management, Maxillofacial Surgeries, Submental Intubation.

HOW TO CITE THIS ARTICLE: Joseph Raajesh I, Deepak Paulose T, Devakumari S. Analysis of methods of airway management in maxillofacial surgeries in a tertiary care centre at Puducherry. J. Evolution Med. Dent. Sci. 2016;5(17):876-878,

DOI: $10.14260 /$ jemds/2016/202

\section{INTRODUCTION}

Airway management plays an important role during maxillofacial surgeries as both surgeon and anaesthesiologist like to share the area of airway. Moreover the corrective procedure demands fixation of fractures, repair of soft tissue injuries and maintaining occlusion, but without compromising the cosmetic aspect. Requirement of checking the dental occlusion intraoperatively precludes the orotracheal intubation making the nasotracheal route the commonest. In cases where the mid face or base of the skull is involved, intubating the trachea through nasopharynx is not without serious risks involved. Tracheostomy was considered as a method of choice for such patients before the widespread availability of fiberoptic bronchoscope. Submental Intubation (SMI) is another option, which can be considered as an alternate to tracheostomy.

Financial or Other, Competing Interest: None.

Submission 11-01-2016, Peer Review 09-02-2016,

Acceptance 15-02-2016, Published 29-02-2016.

Corresponding Author:

Dr. Joseph Raajesh I,

Professor, Department of Anaesthesiology,

Indira Gandhi Medical College \& Research Institute,

Puducherry.

E-mail: ijoerajesh@gmail.com

DOI: $10.14260 /$ jemds/2016/202

\section{MATERIALS}

In this retrospective analysis, all patients of either sex who had been operated for oromaxillofacial procedures between February 2011 and December 2015, at this tertiary care hospital were reviewed. A total of seventy one patients of various etiologies had been operated during this period. All seventy one patients had been operated as elective procedures.

During preoperative evaluation, patients were assessed for type and extent of injury as well as nature of airway status. Airway status was assessed by adequacy of mouth opening as well as Mallampati classification. Associated injuries like head injury had been addressed before accepting them for proposed procedures. Written and informed consent had been obtained with full explanation of the procedure, method of airway management including alternate techniques like submental intubation or tracheostomy if required.

All patients received the standard premedication of oral diazepam $10 \mathrm{mg}$ and ranitidine $150 \mathrm{mg} 8$ hours before the procedure. Airway management and type of technique had been planned as per the type of injury, proposed surgery and patient's airway status. All adult patients received Glycopyrrolate $(0.2 \mathrm{mg})$ and inj. Midazolam $(2 \mathrm{mg})$ prior to induction. 
All patients received standard monitoring, which included ECG, pulse oximetry, non-invasive blood pressure and end tidal carbon-di-oxide monitoring. Since none of the patients were falling under the category of difficult airway, all of them were induced with inj. Propofol in standard doses. Either succinylcholine or vecuronium bromide were used to facilitate intubation depending on the airway status of the patient. Anaesthesia was maintained with Nitrous oxide, Oxygen and Isoflurane. Intraoperative analgesia was achieved with inj. fentanyl/pethidine/morphine. At the end of the procedure, residual paralysis was reversed with inj. neostigmine and glycopyrrolate. After assessing the adequacy of reversal of the neuromuscular blockade, extubation of trachea was performed. Postoperative analgesia was achieved with inj. Diclofenac or inj. Paracetamol. Patients were taken care in high dependency unit postoperatively.

\section{RESULTS}

Overall, seventy one patients were operated at our tertiary care hospital over a period of five years between February 2011 and December 2015. In total of 71 patients, 63(88.7\%) were male and $8(11.3 \%)$ were female (Table 1$)$ making the sex ratio nearly 8:1 with male preponderance.

\begin{tabular}{|c|c|}
\hline Male & Female \\
\hline $63(88.7 \%)$ & $8(11.3 \%)$ \\
\hline \multicolumn{2}{|c|}{ Table 1: Gender Distribution } \\
\hline
\end{tabular}

Table 2 illustrates the distribution of age amongst the patients. Majority of them were in the age group of 31-40 years $22(30.9 \%)$, which is followed by $21-30$ years age group. In these two age groups, the commonest etiology was found to be road traffic accident.

\begin{tabular}{|c|c|}
\hline Age & Number of Patients \\
\hline$<20$ & $8(11.2 \%)$ \\
\hline $21-30$ & $17(23.94 \%)$ \\
\hline $31-40$ & $22(30.9 \%)$ \\
\hline $41-50$ & $14(19.7 \%)$ \\
\hline $51-60$ & $6(8.45 \%)$ \\
\hline $61-70$ & $4(5.6 \%)$ \\
\hline \multicolumn{2}{|c|}{ Table 2: Age Distribution } \\
\hline
\end{tabular}

Table 3 illustrates the etiology of the injury or underlying condition, for which the surgery is performed. Trauma was found to be the most common etiology 56(78.8\%) amongst all procedures. Amongst the fractures, fracture mandible was found to be the most common type of injury in 33 patients (46.4\%) followed by fracture zygoma $8(11.2 \%)$ and maxilla in 2 patients $(2.8 \%) ; 10(14.1 \%)$ patients had more than two fractures. There were pan-facial fractures (more than two fractures of face) in 3 patients $(4.2 \%)$.

\begin{tabular}{|c|c|c|c|}
\hline \multicolumn{2}{|c|}{ Trauma 56 (78.8\%) } & \multicolumn{2}{|c|}{ Non-trauma 15 (21.2\%) } \\
\hline Single fracture & & Tumours of mandible & 4 \\
Mandible & 33 & Maxillary cyst & 2 \\
Zygoma & 8 & & \\
Maxilla & 2 & Secondary procedures & 4 \\
& & & \\
\hline
\end{tabular}

\begin{tabular}{|c|c|c|c|}
\hline $\begin{array}{c}\text { More than one } \\
\text { fracture }\end{array}$ & 10 & $\begin{array}{c}\text { Osteomyelitis of } \\
\text { mandible } \\
\text { Submucous fibrosis }\end{array}$ & 2 \\
\hline Panfacial & 3 & $\begin{array}{c}\text { Chronic sialolith } \\
\text { Trigeminal neuralgia }\end{array}$ & 1 \\
\hline \multicolumn{2}{|c|}{ Table 3: Etiology and Bony Involvement } \\
\hline
\end{tabular}

Table 4 illustrates the method of airway management. Nasal intubation under direct visualization of vocal cords was achieved in 64 patients $(90 \%)$. Submental intubation following oral intubation was performed in seven patients (10\%). Among these seven patients, flexometallic tube was used in four patients and Ring Adair Elwyn (RAE) tube was used in three patients.

\begin{tabular}{|c|c|}
\hline Nasotracheal Intubation & $\mathbf{6 4 ( 9 0 . 1 \% )}$ \\
\hline Submental intubation & $7(9.9 \%)$ \\
Flexometallic tube & 4 \\
RAE tube & 3 \\
\hline \multicolumn{2}{|c|}{ Table 4: Airway Management } \\
\hline
\end{tabular}

\section{DISCUSSION}

As in most of the studies.(1),(2),(3) involving maxillofacial trauma, male sex was involved more in a ratio of 8:1 than females who had undergone these procedures in our institute also. Majority of the patients belonged to the third and fourth decade of the life. The commonest bone involved was mandible (46\%). These three findings are correlating well with an another study done in the other union territory of India.(1) These findings, especially, distribution of age could be explained by the fact that being more active, they are more prone for sustaining trauma. Out of 71 one patients, nearly $79 \%$ of the procedures were performed in patients who sustained injury due to trauma.

For any procedure, the best method of airway management should be well accepted both by surgeon as well as anaesthesiologist. In case of maxillofacial surgeries maintaining occlusion is of paramount importance, as it gives the surgeon a measure of approximation of mandibular and maxillary teeth in all mandibular positions and movements. (4) This surgical requirement of maintaining occlusion throughout the period of procedure rules out the possibility of using oral route for establishment of airway during the operative period. Using nasal route for establishing the airway is a time tested method for surgeries involving oral cavities.

This is the reason nasotracheal intubation constituted the method of airway management in majority of our patients. Unlike elective surgeries like tonsillectomies or palatal surgeries, the possible presence of injuries in the nasopharyngeal route may pose a challenge during nasotracheal intubation, as trauma is the leading cause in oromaxillofacial surgeries. Nasotracheal intubation can be considered as a relative contraindication in patients with mid face injury or base of the skull fractures.(5) In these cases securing airway with Fiberoptic Bronchoscope (FOB) is safe.(6) Prior to the wide spread availability of FOB, tracheostomy was considered as the alternate mode of airway management in these patients.(7) 
However, SMI technique may be considered as a viable option in nasopharyngeal injury when FOB is not available.(8)

This technique was first described in the year 1986 by Hernandez AF. Who described this technique as a valuable alternate to tracheostomy.(9) This practice of passing the endotracheal tube through a submental incision will be particularly helpful if condition of patients does not require any prolonged mechanical ventilation at the end of the surgery.

Among our seventy one patients, SMI was performed in seven patients. Six of them had nasopharyngeal injury and it was done as a planned procedure. In one patient, nasotracheal tube could not be passed and was successfully intubated using submental route. Armoured endotracheal tube has been routinely used whenever SMI was performed albeit with certain modifications. We used oral RAE tubes for the purpose of SMI in a few cases with equal success.(10) The preformed nature of the tube allowed easy passage without any obstruction in those patients. None of the patients in our study period required tracheostomy or cricothyroidotomy. No patients had any major or serious complications in the perioperative period.

\section{CONCLUSION}

As with many studies our study also proves that in maxillofacial procedures, trauma is the leading cause in this part of India also. Other findings that correlate with other studies are male preponderance, maximum patients falling in the third and fourth decade of life. Nasotracheal intubation is the method of choice in securing the airway during the maxillofacial procedures. Submental intubation can be considered as a viable option when nasotracheal intubation is not possible due to the involvement of base of the skull or mid facial fractures.

\section{REFERENCES}

1. Kumar GBA, Dhupar V, Akkara F, et al. Patterns of maxillofacial fractures in Goa. J Maxillofac Oral Surg [Internet]. 2015 Jun [Cited 2015 Dec 15];14(2):138-41. Available from:

http://www.ncbi.nlm.nih.gov/pubmed/26028827.

2. Raval CB, Rashiduddin M. Airway management in patients with maxillofacial trauma - a retrospective study of 177 cases. Saudi J Anaesth [Internet]. 2011 Jan [cited 2016 Jan 10];5(1):9-14. Available from: http://www.pubmedcentral.nih.gov/articlerender.fcgi? artid=3101764\&tool=pmcentrez\&rendertype=abstract.
3. Arangio $\mathrm{P}$, Vellone $\mathrm{V}$, Torre $\mathrm{U}$, et al. Maxillofacial fractures in the province of Latina, Lazio, Italy: review of 400 injuries and 83 cases. J Craniomaxillofac Surg [Internet]. 2014 Jul [Cited 2016 Jan 10];42(5):583-7. Available from:

http://www.ncbi.nlm.nih.gov/pubmed/24035287.

4. Lee SS, Huang SH, Wu SH, et al. A review of intraoperative airway management for midface facial bone fracture patients. Ann Plast Surg [Internet]. 2009 Aug [cited 2016 Jan 5];63(2):162-6. Available from: http://www.ncbi.nlm.nih.gov/pubmed/19542879.

5. Hall CEJ, Shutt LE. Nasotracheal intubation for head and neck surgery. Anaesthesia [Internet]. 2003 Mar [cited 2016 Jan 5];58(3):249-56. Available from: http://www.ncbi.nlm.nih.gov/pubmed/12603455.

6. Arrowsmith JE, Robertshaw HJ, Boyd JD. Nasotracheal intubation in the presence of frontobasal skull fracture. Can J Anaesth = J Can d'anesthésie [Internet]. 1998 Jan [Cited 2016 Jan 11];45(1):71-5. Available from: http://www.ncbi.nlm.nih.gov/pubmed/9466033.

7. Muzzi DA, Losasso TJ, Cucchiara RF. Complication from a nasopharyngeal airway in a patient with a basilar skull fracture. J Am Soc Anesthesiol [Internet]. The American Society of Anesthesiologists; 1991 Feb 1 [cited 2016 Jan 10];74(2):366-7. Available from:

http://anesthesiology.pubs.asahq.org/article.aspx?artic leid=1952112.

8. Jundt JS, Cattano D, Hagberg CA, et al. Submental intubation: a literature review. Int J Oral Maxillofac Surg [Internet]. 2012 Jan [Cited 2016 Jan 10];41(1):46-54. Available from:

http://www.ncbi.nlm.nih.gov/pubmed/21930363.

9. Hernández Altemir F. The submental route for endotracheal intubation. A new technique. J Maxillofac Surg [Internet]. 1986 Feb [cited 2016 Jan 18];14(1):645. Available from: http://www.ncbi.nlm.nih.gov/pubmed/3456416.

10. Raajesh JI, Debendra TK, Shanmugam D, et al. Modification of submental intubation using oral RingAdair-Elwyn tubes in faciomaxillary surgeries: a novel approach. Indian J Anaesth [Internet]. 2013 Jul [Cited 2013 Nov 18];57(4):418-9. Available from: http://www.pubmedcentral.nih.gov/articlerender.fcgi? artid=3800343\&tool=pmcentrez\&rendertype=abstract. 